\title{
Marc Fumaroli, Chateaubriand. Poésie et Terreur
}

\section{Laurence Richer}

\section{(2) OpenEdition}

\section{Journals}

\section{Édition électronique}

URL : http://journals.openedition.org/studifrancesi/36333

DOI : $10.4000 /$ studifrancesi.36333

ISSN : 2427-5856

\section{Éditeur}

Rosenberg \& Sellier

\section{Édition imprimée}

Date de publication : 1 juillet 2005

Pagination : 178-179

ISSN : 0039-2944

\section{Référence électronique}

Laurence Richer, « Marc Fumaroli, Chateaubriand. Poésie et Terreur », Studi Francesi [En ligne], 145 (XLIX | I) | 2005, mis en ligne le 30 novembre 2015, consulté le 20 avril 2021. URL : http://

journals.openedition.org/studifrancesi/36333; DOI : https://doi.org/10.4000/studifrancesi.36333

\section{Ce document a été généré automatiquement le 20 avril 2021.}

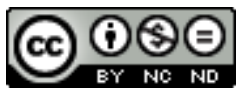

Studi Francesi è distribuita con Licenza Creative Commons Attribuzione - Non commerciale - Non opere derivate 4.0 Internazionale. 


\title{
Marc Fumaroli, Chateaubriand. Poésie et Terreur
}

\author{
Laurence Richer
}

\section{RÉFÉRENCE}

MARC FUmARoli, Chateaubriand. Poésie et Terreur, Paris, Éditions de Fallois, 2003, pp. 799.

1 Marc Fumaroli n'est pas toujours tendre avec Sainte-Beuve. Pourtant le rapprochement s'impose. C'est un Chateaubriand et son temps qu'il nous livre, en ce début de siècle qui, loin des dédains ou des querelles du $\mathrm{XX}^{\mathrm{e}}$ siècle, revisite l'histoire littéraire. C'est la synthèse d'une longue fréquentation de Chateaubriand, déjà marquée par de brillants travaux (on pense en particulier au colloque Chateaubriand et les arts, en 1999).

2 Le style étincelant est un palimpseste de Chateaubriand, l'empathie étant particulièrement nette dans la construction, rigoureuse et complexe, qui parvient à unifier une série d'études, autonomes à l'origine. Les titres des chapitres, brillants et synthétiques, sont certes de bonnes clefs pour qui voudra entrer dans ce livre. Il n'empêche que les chemins de traverse, découverts au fil de la lecture, sont aussi nombreux que dans les Mémoires d'outre-tombe. Les rapports aux autres constituent une des lignes de force du livre. Marc Fumaroli donne vie à une époque et ne refuse ni le détail biographique ni la précision du vécu. Le livre est, en ce sens, accessible à un vaste lectorat. Mais il sait toujours conduire sur les chemins de la création littéraire. On y retrouve la très attendue madame Récamier dans un rôle de muse, sans que soit jamais perdue de vue la genèse des Mémoires. On y retrouve surtout les grandes affinités intellectuelles: parmi les plus connues, les brillants passages consacrés à Fontanes et Ballanche font espérer que, quelque jour, Fumaroli traite aussi des rapports de Chateaubriand et Joubert (mentionné p. 136, mais on pourrait en espérer plus). Parmi les affinités moins célèbres, l'analyse des rapports de Chateaubriand et de Tocqueville va à l'essentiel dans un secteur où l'attention a trop souvent été détournée par l'anecdotique. Le rapprochement permet une remarquable analyse sur le danger pour 
l'écrivain d'«aliéner la parole à l'expression solipsiste de son trouble intime [...] en se posant contre le sens commun, la parole de la singularité absolue consent indirectement au despotisme absolu, quand elle ne l'appelle pas» (p. 732).

3 Ce livre propose un style et une étude que l'on peut appeler «classiques». Un de ses nombreux mérites est de rappeler qu'une telle approche est compatible avec l'ouverture de pistes de lecture et de recherche. On serait tenté de penser à ces fructueuses relectures d'œuvres musicales du XIX siècle faites par des chefs ou interprètes formés à l'esthétique baroque: le Chateaubriand que nous offre Marc Fumaroli est à la fois classique et neuf. Sa critique situe Chateaubriand dans une continuité rhétorique et artistique aussi importante chez lui que peu étudiée jusqu’à présent. Elle dit aussi le mouvement constant d'une pensée tournée vers l'avenir autant que vers le passé.

4 Comme la dédicace à Paul Bénichou le souligne, le livre se situe dans l'exploration de la sacralité du monde moderne, qui ne se limite pas, pour Chateaubriand, à son "catholicisme de cœur». Il se veut une somme. Dans les domaines mêmes qui ne sont pas au premier plan des préoccupations de Marc Fumaroli, comme la pensée ou l'action politiques, il nous livre de brillantes synthèses. Dans les domaines de réflexion habituels à l'auteur, de vastes perspectives sont ouvertes. Ainsi, le titre est expliqué par une réflexion sur le «choix de la prose» par Chateaubriand, qui se serait pourtant voulu poète, mais aurait ressenti l'impossibilité du langage poétique, lié à l'ordre classique et monarchique (p. 165): l'irruption de la Terreur dans l'histoire mène à une redéfinition de la littérature. Chateaubriand poète et auteur de Mémoires, écrivain et homme politique: le livre de Marc Fumaroli rend compte de la richesse d'une œuvre.que la critique peine si souvent à saisir dans son ampleur. 